\title{
Catalytic Pyrolysis as a Technology to Dispose of Herbal Medicine Waste
}

\author{
Younghyun Lee ${ }^{1}$, Soosan Kim ${ }^{1}$, Jisu Kim ${ }^{2}$, Gwy-Am Shin ${ }^{1,2}$, Chang-Gu Lee ${ }^{1,2}$, \\ Seungho Jung ${ }^{1,2, *}$ and Jechan Lee ${ }^{1,2, * \text { (D) }}$ \\ 1 Department of Environmental Engineering, Ajou University, Suwon 16499, Korea; \\ dudgus9931@ajou.ac.kr (Y.L.); ksoosan@ajou.ac.kr (S.K.); gwyam@ajou.ac.kr (G.-A.S.); \\ changgu@ajou.ac.kr (C.-G.L.) \\ 2 Department of Environmental and Safety Engineering, Ajou University, Suwon 16499, Korea; \\ kjs980327@ajou.ac.kr \\ * Correspondence: processsafety@ajou.ac.kr (S.J.); jlee83@ajou.ac.kr (J.L.)
}

Received: 25 June 2020; Accepted: 20 July 2020; Published: 23 July 2020

\begin{abstract}
The use of herbal medicine has increased tremendously over the last decades, generating a considerable amount of herbal medicine waste. Pyrolysis is a promising option to dispose of biomass and organic waste such as herbal medicine waste. Herein, an activated carbon-supported Pt catalyst (Pt/AC) and carbon dioxide $\left(\mathrm{CO}_{2}\right)$ were applied to the pyrolysis of real herbal medicine waste to develop a thermal disposal method to prevent the formation of benzene derivatives that are harmful to the environment and human health. When using the Pt/AC catalyst in the pyrolysis of the herbal medicine waste at $500{ }^{\circ} \mathrm{C}$, the generation of benzyl species was suppressed. This was likely because the $\mathrm{Pt}$ catalytic sites accelerate a free radical mechanism that is dominant in the thermal cracking of carbonaceous substances. However, the employment of $\mathrm{CO}_{2}$ (instead of typically used $\mathrm{N}_{2}$ ) as a pyrolysis medium for the herbal medicine waste pyrolysis did not decrease the concentrations of benzyl compounds contained in the pyrolytic products of the herbal medicine waste. This study might help develop a method to thermally dispose of agricultural biowaste, preventing the formation of harmful chemicals to the environment and human beings.
\end{abstract}

Keywords: herbal medicine; thermochemical process; waste disposal; $\mathrm{CO}_{2}$ utilization; catalytic pyrolysis

\section{Introduction}

Herbal medicines have been used since ancient times to treat many health conditions. Presently, the herbal pharmaceutical industry is one of the oldest medical care systems in the world. According to the World Health Organization, approximately $70 \%$ to $80 \%$ of people globally rely on herbal medicines for their health care [1]. Presently, demand for herbal medicines for the treatment of health conditions is increasing, which enhances the market of herbal medicines. The global market size of herbal medicines in 2016 was USD 71 billion [2], and it is expected to reach USD 130 billon by 2023 with a compound annual growth rate of $5.88 \%$ [3].

The increasing demand for herbal medicines leads to the generation of large amounts of solid waste from the extraction processing of herbal medicines. At present, herbal medicine waste is optionally discharged or treated via landfill [4]. However, herbal medicine waste contains benzene derivatives [5] that are toxic, carcinogenic, mutagenetic, and teratogenic, thereby having adverse effects on human health [6]. When benzene derivatives are released into the environment, they can enter into the human body through ingestion and dermal contact [7]. Therefore, the herbal medicine waste discharging and landfilling must be avoided. The use of herbal medicine waste as an organic fertilizer is an alternative method for its disposal [8]; however, it can negatively affect the properties of 
groundwater and soil [4]. Therefore, it is highly necessary to find a way to dispose of herbal medicine waste that does not have a harmful impact on the environment and human health.

Pyrolysis, a thermal process to decompose carbonaceous substances under inert atmosphere (i.e., flowing inert gas such as nitrogen $\left(\mathrm{N}_{2}\right)$ through pyrolyzer), has been recommended for a method to dispose various organic wastes $[9,10]$. It is typically used to make liquid fuels (i.e., bio-oil) [11-13], solid fuels (i.e., charcoal) [14-16], and carbon materials for a variety of applications [17-20]. Other than these typical applications of pyrolysis, pyrolysis with modification (the use of a supported metal catalyst, the use of alternative pyrolysis medium, etc.) has recently been suggested as a process that can dispose of waste materials not only with less emissions of harmful pollutants but also with an effective reduction of waste volume. For example, it was shown that a Pt catalyst supported on activated carbon effectively reduced the emission of benzene derivatives and polycyclic compounds from pyrolyzing polyethylene terephthalate waste [21]. Using carbon dioxide $\left(\mathrm{CO}_{2}\right)$ as a pyrolysis medium instead of $\mathrm{N}_{2}$ had an effect on suppressing their formations during the pyrolysis of food waste [22]. Furthermore, when using both the supported metal catalyst and $\mathrm{CO}_{2}$ in pyrolysis, the effect on suppressing the formation of cyclic compounds such as a benzene derivatives was more enhanced than when using either of the two [23]. As mentioned earlier, herbal medicine waste contains benzene derivatives that are harmful to the environment and human health. Thus, it could be hypothesized that a simultaneous use of $\mathrm{Pt}$ catalyst and $\mathrm{CO}_{2}$ in pyrolysis allows the disposal of herbal medicine waste while minimizing the generation of benzene derivatives.

Based on the hypothesis, an activated carbon-supported $\mathrm{Pt}$ catalyst $(\mathrm{Pt} / \mathrm{AC})$-catalyzed pyrolysis of real herbal medicine waste under $\mathrm{CO}_{2}$ atmosphere was performed. A Pt/AC catalyst was selected because of its high thermal stability at the conditions at which pyrolysis occurs [24-26]. Although herbal medicine waste is one of the most generated wastes in the world with continuously increasing generation, most studies on treating herbal medicine waste are limited to composting and landfilling; very few studies have been conducted to treat herbal medicine waste via a thermochemical process such as pyrolysis. To the best of the authors' knowledge, this is the first study into the effects of using a supported metal catalyst and pyrolysis medium on the pyrolysis of real herbal medicine waste. In order to explore the effects of $\mathrm{Pt} / \mathrm{AC}$ catalyst and $\mathrm{CO}_{2}$ on the formation of benzene derivatives in the pyrolysis of herbal medicine waste, four different cases were considered: (1) pyrolysis without catalyst under a typical inert atmosphere $\left(\mathrm{N}_{2}\right)$; (2) pyrolysis with Pt/AC catalyst under $\mathrm{N}_{2}$ atmosphere; (3) pyrolysis without catalyst under $\mathrm{CO}_{2}$ atmosphere; and (4) pyrolysis with $\mathrm{Pt} / \mathrm{AC}$ catalyst under $\mathrm{CO}_{2}$ atmosphere. The results can help establish an eco-friendly process to dispose of herbal medicine waste.

\section{Results and Discussion}

Table 1 shows the results of proximate, ultimate, and component analyses of the herbal medicine waste. Figure 1 shows the raw herbal medicine waste and treated one for the experiments. The contents of moisture, volatile matter, fixed matter, and ash in the herbal medicine waste and its elemental composition were comparable with other agricultural biomass wastes such as wheat straw and rice husk [27]. Sulfur was not detected in the herbal medicine waste. Its lignin content was $23.5 \mathrm{wt} \%$.

Table 1. Proximate and ultimate characterization of the herbal medicine waste.

\begin{tabular}{cc}
\hline \multicolumn{2}{c}{ Proximate analysis $(\mathrm{wt} \%)$} \\
\hline Moisture & 7.7 \\
\hline Volatile matter & 80.4 \\
\hline Fixed matter & 9.3 \\
\hline Ash & 2.6 \\
\hline Ultimate analysis (wt \%) \\
\hline C
\end{tabular}


Table 1. Cont.

\begin{tabular}{cc}
\hline $\mathrm{H}$ & 6.1 \\
\hline $\mathrm{O}$ & 45.8 \\
\hline $\mathrm{N}$ & 1.5 \\
\hline $\mathrm{S}$ & $\mathrm{N} . \mathrm{D}$. \\
\hline Component analysis (wt \%) \\
\hline Cellulose & 26.1 \\
\hline Hemicellulose & 19.2 \\
\hline Lignin & 23.5 \\
\hline
\end{tabular}

(a)

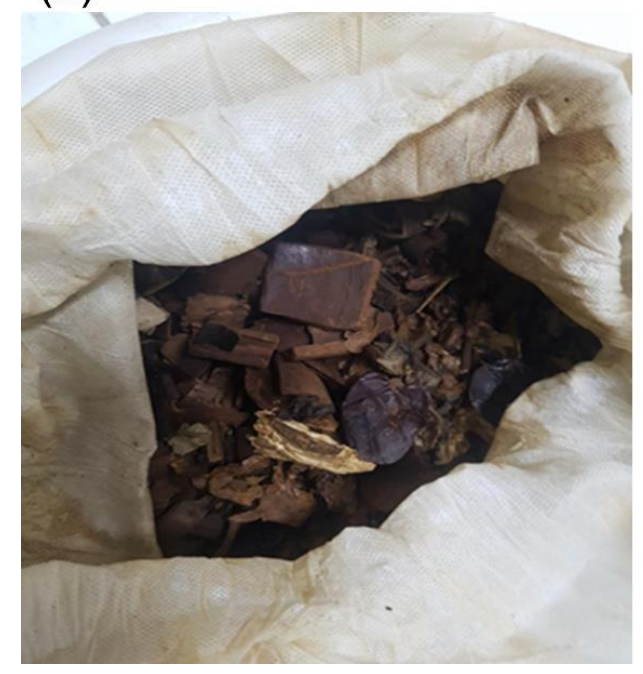

(b)

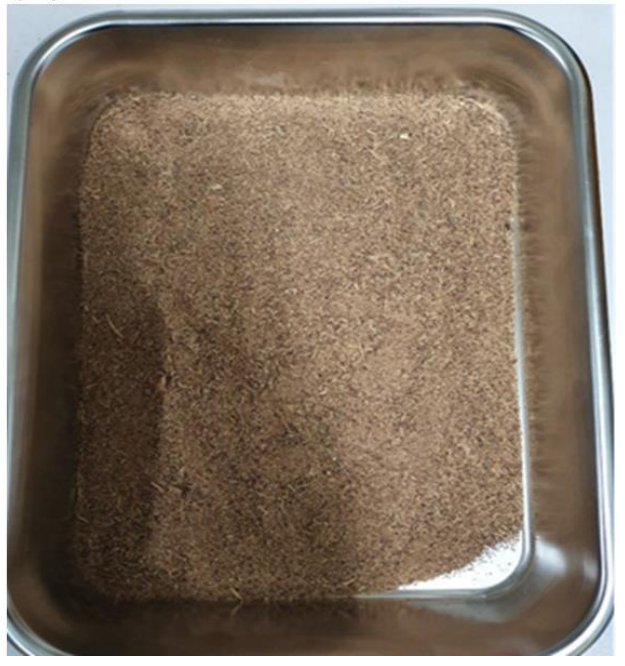

Figure 1. (a) Raw herbal medicine waste; (b) pulverized sieved powder of the herbal medicine waste dried at $60^{\circ} \mathrm{C}$ for $1 \mathrm{~d}$.

The $\mathrm{Pt} / \mathrm{AC}$ catalyst used in this study was characterized using hydrogen chemisorption, nitrogen physisorption, and transmission electronic microscopy (TEM). Hydrogen chemisorption data were used to estimate the dispersion and mean particle sizes of $\mathrm{Pt}$ on the catalyst surface. Nitrogen physisorption data were used to estimate the surface area, average pore size, and total pore volume of the $\mathrm{Pt} / \mathrm{AC}$ catalyst. The average size of Pt nanoparticles was determined using TEM analysis. A representative TEM image is provided in Figure S1a. The particle size distribution of the Pt/AC catalyst is given in Figure S1b. The average Pt particle size was $2.4 \mathrm{~nm}$ for the Pt/AC catalyst. The physicochemical properties of the Pt/AC catalyst are listed in Table 2.

Table 2. Physicochemical properties of the activated carbon-supported $\mathrm{Pt}(\mathrm{Pt} / \mathrm{AC})$ catalyst.

\begin{tabular}{|c|c|}
\hline Pt loading (wt \%) & 5 \\
\hline Pt dispersion (\%) & 49.4 \\
\hline Average Pt particle size ${ }^{a}(\mathrm{~nm})$ & 2.4 \\
\hline Pt particle size ${ }^{b}(\mathrm{~nm})$ & 2.27 \\
\hline Specific surface area $\left(\mathrm{m}^{2} \mathrm{~g}^{-1}\right)$ & 1608.3 \\
\hline Average pore diameter (nm) & 4.7 \\
\hline Total pore volume $\left(\mathrm{cm}^{3} \mathrm{~g}^{-1}\right)$ & 0.98 \\
\hline
\end{tabular}

a Pt particle size measured by TEM. ${ }^{\mathrm{b}}$ Pt particle size measured by estimatation based on hydrogen chemisorption. For this estimation, the structure of $\mathrm{Pt}$ was assumed to be face-centered cubic (fcc). 
Table 3 summarizes the information and concentrations of benzene derivatives identified in the pyrolytic products of the herbal medicine waste. The generated benzene derivatives can be harmful to both human beings and the environment. For example, 1,2-benzenediol is toxic, carcinogenic, and mutagenic, and it causes eye damage and skin corrosion [28]. 1,4-Benzenediol has acute toxicity, causes serious eye damage, and is hazardous to the aquatic environment [29]. 2,3-Benzopyrrole has dermal acute toxicity [30]. Therefore, the generation of such compounds should be minimized (ideally avoided) for the disposal of herbal medicine waste. Table 4 also summarizes the information and concentrations of chemical compounds that do not have a benzene ring identified in the pyrolytic products obtained from the four different herbal medicine waste pyrolysis experiments.

Figure 2 presents the yield of pyrolytic liquid and residual solid at four different pyrolysis conditions. The yield was obtained by the following procedure: (1) weighing the mass of liquid collected during the pyrolysis and (2) weighing the mass of solid residue after the pyrolysis. The use of the Pt/AC catalyst and the kind of pyrolysis medium had little effects on the mass portion of gas, liquid, and solid products. Note that the residence time of the herbal medicine waste in the pyrolysis reactor did not affect the distributions of benzene derivatives in the pyrolytic products. 1,2-Benzenediol and 1,4-benznediol were not detected in the pyrolytic product obtained via the herbal medicine waste pyrolysis under $\mathrm{N}_{2}$ atmosphere. Both 1,2-benzenediol and 1,4-benzenediol most likely originated from the natural phenolic compounds (flavonoids, stilbenes, tannins, etc.) that are contained in medicinal herbs [31]. The depolymerization, dehydration, and rearrangement of the natural phenolic compounds successively or simultaneously occurring lead to the formation of 1,2-benzenediol and 1,4-benzenediol [32,33]. This meant that the use of $\mathrm{CO}_{2}$ in the pyrolysis of the herbal medicine waste hinders the successive or simultaneous depolymerization, dehydration, and rearrangement of the natural phenolic compounds. 2-Methyl-2-phenyl-1,2,3,7-tetrahydro-[1,2,4]triazolo[1,5-a][1,3,5]triazin-5-amine (entry 12 in Table 3) was the most produced among the benzene derivatives, accounting for $56 \%$ and $49 \%$ of the herbal medicine waste pyrolysis in $\mathrm{N}_{2}$ and the herbal medicine waste pyrolysis in $\mathrm{CO}_{2}$, respectively. Stigmastan-3,5-diene (entry 14 in Table 4) accounted for about 10\% of the pyrolytic products of the herbal medicine waste produced under $\mathrm{N}_{2}$ and $\mathrm{CO}_{2}$ atmospheres. Stigmasta-3,5-diene likely originated from $\beta$-sitosterol, which was produced via high-temperature reactions of $\beta$-sitosterol $\left(>150{ }^{\circ} \mathrm{C}\right)[34,35]$. Note that $\beta$-sitosterol is a main component of herbal medicines [36]. The contents of the other benzyl compounds found in the pyrolytic products ranged from $1 \%$ to $7 \%$. 
Table 3. Benzene derivatives identified in the pyrolytic products generated from the pyrolysis of the herbal medicine waste and their concentrations obtained from four different pyrolysis experiments. Mean values of replicates $(n=3)$ are reported and standard deviations of the mean values are around $7 \%$.

\begin{tabular}{|c|c|c|c|c|c|c|c|c|}
\hline \multirow[b]{2}{*}{ Entry } & \multirow[b]{2}{*}{ Chemical Name } & \multirow[b]{2}{*}{$\begin{array}{l}\text { Chemical } \\
\text { Formula }\end{array}$} & \multirow[b]{2}{*}{ MW } & \multirow[b]{2}{*}{ Chemical Structure } & \multicolumn{4}{|c|}{ Apparent Concentration a ${ }^{2}(\mathrm{ppm}$, Weight Basis) } \\
\hline & & & & & $\begin{array}{c}\mathrm{N}_{2} \text { without } \\
\text { Catalyst }\end{array}$ & $\begin{array}{l}\mathrm{N}_{2} \text { with } \\
\text { Catalyst }\end{array}$ & $\begin{array}{c}\mathrm{CO}_{2} \text { without } \\
\text { Catalyst }\end{array}$ & $\begin{array}{c}\mathrm{CO}_{2} \text { with } \\
\text { Catalyst }\end{array}$ \\
\hline 1 & 1,2-Benzenediol & $\mathrm{C}_{6} \mathrm{H}_{6} \mathrm{O}_{2}$ & 110.11 & & 0 & 0 & 180 & 170 \\
\hline 2 & 1,4-Benzenediol & $\mathrm{C}_{6} \mathrm{H}_{6} \mathrm{O}_{2}$ & 110.11 & & 0 & 0 & 300 & 270 \\
\hline 3 & 2,3-Benzopyrrole & $\mathrm{C}_{8} \mathrm{H}_{7} \mathrm{~N}$ & 117.15 & & 72 & 75 & 87 & 65 \\
\hline 4 & Benzo[h]quinoline & $\mathrm{C}_{13} \mathrm{H}_{9} \mathrm{~N}$ & 179.22 & & 99 & 130 & 90 & 91 \\
\hline 5 & $\begin{array}{l}\text { 2,3-Dihydro-2-(1-methylethenyl)-7H-furo } \\
\text { [3,2-g][1]benzopyran-7-one }\end{array}$ & $\mathrm{C}_{14} \mathrm{H}_{12} \mathrm{O}_{3}$ & 228.24 & & 140 & 86 & 120 & 260 \\
\hline 6 & $\begin{array}{l}\text { (S)-7,8-Dihydro-7-hydroxy- } \\
\text { 8,8-dimethyl-2H,6H-benzo(1,2-b:5,4--b')dipyran-2-one }\end{array}$ & $\mathrm{C}_{14} \mathrm{H}_{14} \mathrm{O}_{4}$ & 246.26 & & 200 & 91 & 260 & 270 \\
\hline 7 & (E)-4-(2,2-Dimethyl-2H-chromen-3-yl)but-3-en-2-one & $\mathrm{C}_{15} \mathrm{H}_{16} \mathrm{O}_{2}$ & 228.29 & & 390 & 340 & 410 & 410 \\
\hline 8 & $\begin{array}{l}\text { 2-(1-Hydroxy-1-methylethyl)-2,3-dihydrofuro[3,2-g] } \\
\text { chromen-7-one }\end{array}$ & $\mathrm{C}_{14} \mathrm{H}_{14} \mathrm{O}_{4}$ & 246.26 & & 160 & 140 & 150 & 120 \\
\hline 9 & 4,4,9-Trimethylnaphtho[1,2-b]furan-5(4H)-one & $\mathrm{C}_{15} \mathrm{H}_{14} \mathrm{O}_{2}$ & 226.27 & & 640 & 580 & 640 & 970 \\
\hline
\end{tabular}


Table 3. Cont.

\begin{tabular}{|c|c|c|c|c|c|c|c|c|}
\hline \multirow[b]{2}{*}{ Entry } & \multirow[b]{2}{*}{ Chemical Name } & \multirow[b]{2}{*}{$\begin{array}{l}\text { Chemical } \\
\text { Formula }\end{array}$} & \multirow[b]{2}{*}{ MW } & \multirow[b]{2}{*}{ Chemical Structure } & \multicolumn{4}{|c|}{ Apparent Concentration ${ }^{\mathrm{a}}(\mathrm{ppm}$, Weight Basis) } \\
\hline & & & & & $\begin{array}{c}\mathrm{N}_{2} \text { without } \\
\text { Catalyst }\end{array}$ & $\begin{array}{l}\mathbf{N}_{2} \text { with } \\
\text { Catalyst }\end{array}$ & $\begin{array}{c}\mathrm{CO}_{2} \text { without } \\
\text { Catalyst }\end{array}$ & $\begin{array}{l}\mathrm{CO}_{2} \text { with } \\
\text { Catalyst }\end{array}$ \\
\hline 10 & $2 H, 8 H$-Benzo[1,2-b:5,4-b' ${ }^{\prime}$ dipyran-2-one & $\mathrm{C}_{12} \mathrm{H}_{8} \mathrm{O}_{3}$ & 200.19 & & 340 & 260 & 380 & 450 \\
\hline 11 & $\begin{array}{l}\text { N-isopropyl-1,6-dimethyl-2-methylene- } \\
\text { 1,2-dihydroquinolin-5-amine }\end{array}$ & $\mathrm{C}_{15} \mathrm{H}_{20} \mathrm{~N}_{2}$ & 228.33 & & 190 & 130 & 290 & 260 \\
\hline 12 & $\begin{array}{l}\text { 2-Methyl-2-phenyl-1,2,3,7-tetrahydro- } \\
{[1,2,4] \text { triazolo[1,5-a][1,3,5]triazin-5-amine }}\end{array}$ & $\mathrm{C}_{11} \mathrm{H}_{14} \mathrm{~N}_{6}$ & 230.27 & & 3800 & 3300 & 3500 & 3300 \\
\hline
\end{tabular}

${ }^{a}$ Apparent concentration was determined by GC-MS using phenol as an internal standard.

Table 4. Chemical compounds that do not have a benzene ring identified in the pyrolytic products generated from the pyrolysis of the herbal medicine waste and their concentrations obtained from four different pyrolysis experiments. Mean values of replicates $(n=3)$ are reported and standard deviations of the mean values of around $7 \%$.

\begin{tabular}{|c|c|c|c|c|c|c|c|c|}
\hline \multirow[b]{2}{*}{ Entry } & \multirow[b]{2}{*}{ Chemical Name } & \multirow[b]{2}{*}{$\begin{array}{l}\text { Chemical } \\
\text { Formula }\end{array}$} & \multirow[b]{2}{*}{ MW } & \multirow[b]{2}{*}{ Chemical Structure } & \multicolumn{4}{|c|}{ Apparent Concentration ${ }^{\mathrm{a}}(\mathrm{ppm}$, Weight Basis) } \\
\hline & & & & & $\begin{array}{c}\mathrm{N}_{2} \text { without } \\
\text { Catalyst }\end{array}$ & $\begin{array}{l}\mathrm{N}_{2} \text { with } \\
\text { Catalyst }\end{array}$ & $\begin{array}{l}\mathrm{CO}_{2} \text { without } \\
\text { Catalyst }\end{array}$ & $\begin{array}{l}\mathrm{CO}_{2} \text { with } \\
\text { Catalyst }\end{array}$ \\
\hline 1 & Caprolactam & $\mathrm{C}_{6} \mathrm{H}_{11} \mathrm{NO}$ & 113.16 & & 0 & 0 & 230 & 50 \\
\hline 2 & Pyrrolo $[1,2, a]$ pyrazine-1,4-dione & $\mathrm{C}_{7} \mathrm{H}_{4} \mathrm{~N}_{2} \mathrm{O}_{2}$ & 148.12 & & 76 & 41 & 120 & 100 \\
\hline 3 & 3,9 Diazatricyclo [7.3.0.0(3,7)] dodecan-2,8-dione & $\mathrm{C}_{10} \mathrm{H}_{14} \mathrm{~N}_{2} \mathrm{O}_{2}$ & 194.23 & & 210 & 150 & 280 & 250 \\
\hline
\end{tabular}


Table 4. Cont.

\begin{tabular}{|c|c|c|c|c|c|c|c|c|}
\hline \multirow[b]{2}{*}{ Entry } & \multirow[b]{2}{*}{ Chemical Name } & \multirow[b]{2}{*}{$\begin{array}{l}\text { Chemical } \\
\text { Formula }\end{array}$} & \multirow[b]{2}{*}{ MW } & \multirow[b]{2}{*}{ Chemical Structure } & \multicolumn{4}{|c|}{ Apparent Concentration ${ }^{\mathrm{a}}(\mathrm{ppm}$, Weight Basis $)$} \\
\hline & & & & & $\begin{array}{c}\mathrm{N}_{2} \text { without } \\
\text { Catalyst }\end{array}$ & $\begin{array}{l}\mathrm{N}_{2} \text { with } \\
\text { Catalyst }\end{array}$ & $\begin{array}{c}\mathrm{CO}_{2} \text { without } \\
\text { Catalyst }\end{array}$ & $\begin{array}{l}\mathrm{CO}_{2} \text { with } \\
\text { Catalyst }\end{array}$ \\
\hline 4 & Palmitic acid & $\mathrm{C}_{16} \mathrm{H}_{32} \mathrm{O}_{2}$ & 256.42 & & 340 & 270 & 200 & 260 \\
\hline 5 & Americanolide D & $\mathrm{C}_{15} \mathrm{H}_{20} \mathrm{O}_{2}$ & 232.32 & & 150 & 130 & 190 & 210 \\
\hline 6 & 9,12-Octadecadienoic acid & $\mathrm{C}_{18} \mathrm{H}_{32} \mathrm{O}_{2}$ & 280.45 & & 81 & 85 & 81 & 75 \\
\hline 7 & 9-Octadecenoic acid & $\mathrm{C}_{18} \mathrm{H}_{34} \mathrm{O}_{2}$ & 282.46 & & 960 & 760 & 530 & 370 \\
\hline 8 & Stearic acid & $\mathrm{C}_{18} \mathrm{H}_{36} \mathrm{O}_{2}$ & 284.48 & & 160 & 190 & 100 & 140 \\
\hline 9 & 1-Hexadecene & $\mathrm{C}_{16} \mathrm{H}_{32}$ & 224.43 & & 99 & 100 & 0 & 0 \\
\hline 10 & 9-Octadecenamide & $\mathrm{C}_{18} \mathrm{H}_{35} \mathrm{NO}$ & 281.48 & & 190 & 64 & 0 & 0 \\
\hline 11 & 3-Methyl-but-2-enoic acid & $\mathrm{C}_{5} \mathrm{H}_{8} \mathrm{O}_{2}$ & 100.12 & & 2100 & 1700 & 1800 & 1200 \\
\hline 12 & Tetracosa-2,6,10,14,18,22-hexaene & $\mathrm{C}_{24} \mathrm{H}_{38}$ & 326.56 & & 99 & 110 & 0 & 0 \\
\hline 13 & Eicosane & $\mathrm{C}_{20} \mathrm{H}_{42}$ & 282.55 & & 120 & 170 & 73 & 59 \\
\hline 14 & Stigmastan-3,5-diene & $\mathrm{C}_{29} \mathrm{H}_{48}$ & 396.69 & & 760 & 830 & 720 & 590 \\
\hline
\end{tabular}

a Apparent concentration was determined by GC-MS using phenol as an internal standard. 


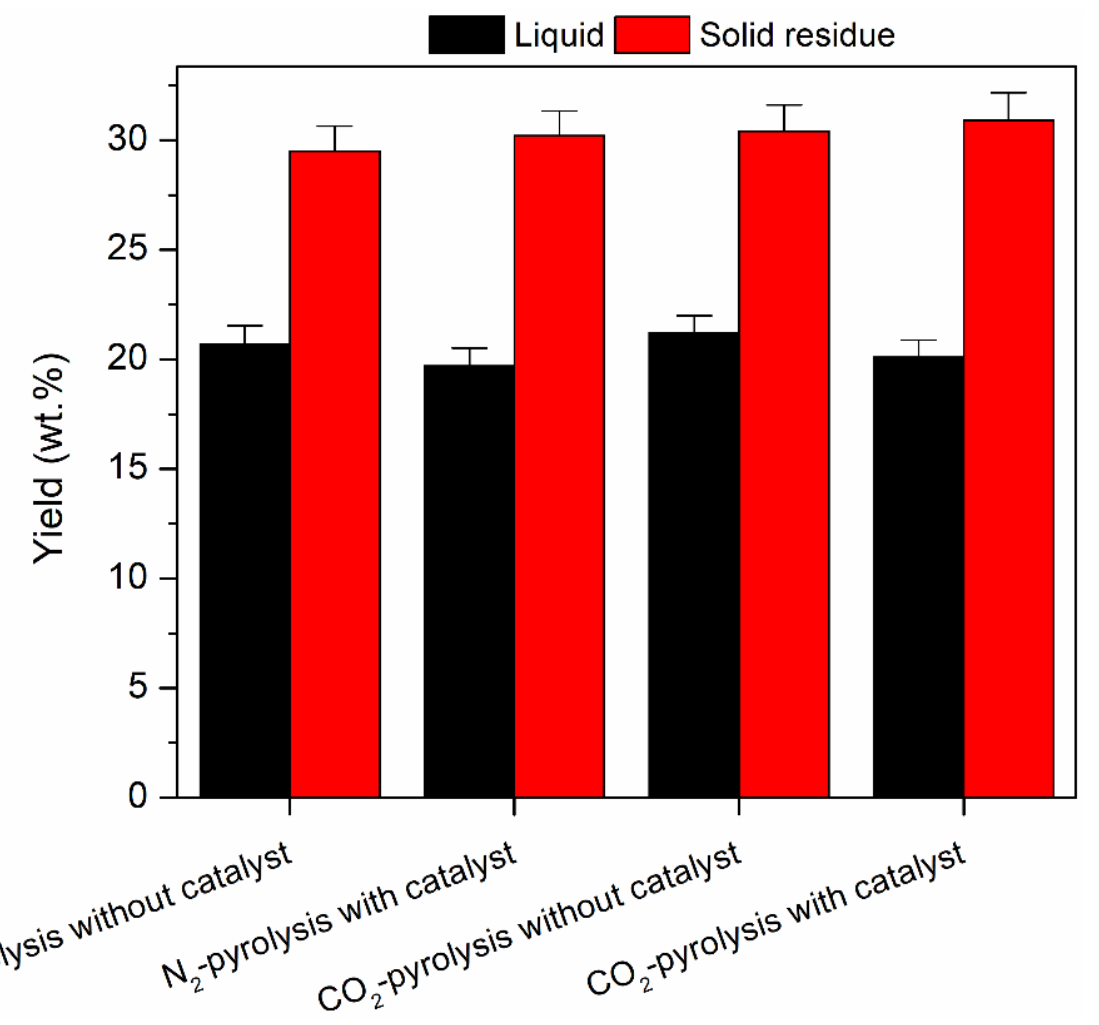

Figure 2. Liquid and residual solid yields obtained from four different pyrolysis experiments. Mean values of replicates $(n=3)$ are reported with standard deviations given as error bars.

As in the case of non-catalytic pyrolysis of the herbal medicine waste, 1,2-benzenediol and 1,4-benzenediol were only observed in the pyrolytic product of the herbal medicine waste produced from the $\mathrm{CO}_{2}$ pyrolysis. In other words, the effect of $\mathrm{CO}_{2}$ on the generation of the benzenediols for the pyrolysis of the herbal medicine waste (i.e., hindrance of successive or simultaneous depolymerization, dehydration, and rearrangement) was regardless of the use of the Pt catalyst. Overall product distributions of the pyrolytic products of the herbal medicine waste made without the Pt catalyst were comparable to those with the Pt catalyst.

When using the Pt catalyst in the pyrolysis of the herbal medicine waste, high contents of relatively light compounds (e.g., 2,3-benzopyrrole and benzo[ $h]$ quinoline) were obtained. Similar trends were observed for the $\mathrm{CO}_{2}$ pyrolysis with and without the Pt/AC catalyst. This indicted that the Pt catalyst is effective at cracking heavy compounds evolved during the pyrolysis of the herbal medicine waste. This could be explained by a free radical mechanism that is dominant in the thermal cracking of hydrocarbons [37]. In the mechanism, the feedstock molecule loses a hydrogen atom by thermally caused collision and reaction with a small hydrocarbon radical, making a free radical itself. The free radical undergoes isomerization prior to cracking, or it immediately cracks. Isomerization of the radical changes the position of a hydrogen atom, which yields a more stable radical. Thermal cracking of the original or isomerized radical occurs at the $\mathrm{C}-\mathrm{C}$ bond located in a $\beta$-position to the carbon atom, which lacks a hydrogen atom. A primary carbon atom lacks a hydrogen atom (i.e., a primary radical) via thermal cracking at the $\beta$-position. In this step, no change in the position of the hydrogen atom takes place with respect to the carbon skeleton. Thermal cracking of the primary radical leads to the formation of another primary radical. The radicals ultimately are reduced to methyl or ethyl fragments through successive re-cracking. Then, these radicals react with feedstock molecules to produce new free radicals and are themselves converted to light molecules (i.e., thermal cracking propagated as a chain reaction). $\mathrm{Pt}$ sites on the $\mathrm{Pt} / \mathrm{AC}$ catalyst likely accelerate the thermal free radical 
mechanism during the pyrolysis of the herbal medicine waste. Furthermore, Pt catalysts can be more stable during the pyrolysis of the herbal medicine waste because they do not favor coke formation [38].

Figure 3 compares the total concentrations of benzyl compounds found in the pyrolytic products of the herbal medicine waste made by four different pyrolysis experiments. The difference between the total concentration of benzyl compounds obtained by the $\mathrm{CO}_{2}$-pyrolysis without the Pt catalyst and those obtained by the $\mathrm{CO}_{2}$-pyrolysis with the Pt catalyst was not statistically significant, based on the Student's $t$-test at a $95 \%$ confidence limit. However, the total concentration of benzyl compounds obtained by the $\mathrm{N}_{2}$ pyrolysis was significantly lower than those obtained by the $\mathrm{CO}_{2}$-pyrolysis $(95 \%$ confidence limit using the Student's $t$-test). Overall, the total concentration of benzyl compounds was decreased in the order: $\mathrm{CO}_{2}$-pyrolysis without the Pt catalyst $>\mathrm{CO}_{2}$-pyrolysis with the Pt catalyst $>\mathrm{N}_{2}$-pyrolysis without the Pt catalyst $>\mathrm{N}_{2}$-pyrolysis with the Pt catalyst. The Pt-catalyzed pyrolysis of the herbal medicine waste under $\mathrm{N}_{2}$ atmosphere generated the fewest benzene derivatives. The results clearly indicated that the formation of benzene derivatives in the pyrolysis of the herbal medicine waste is most susceptible to the use of the Pt catalyst.

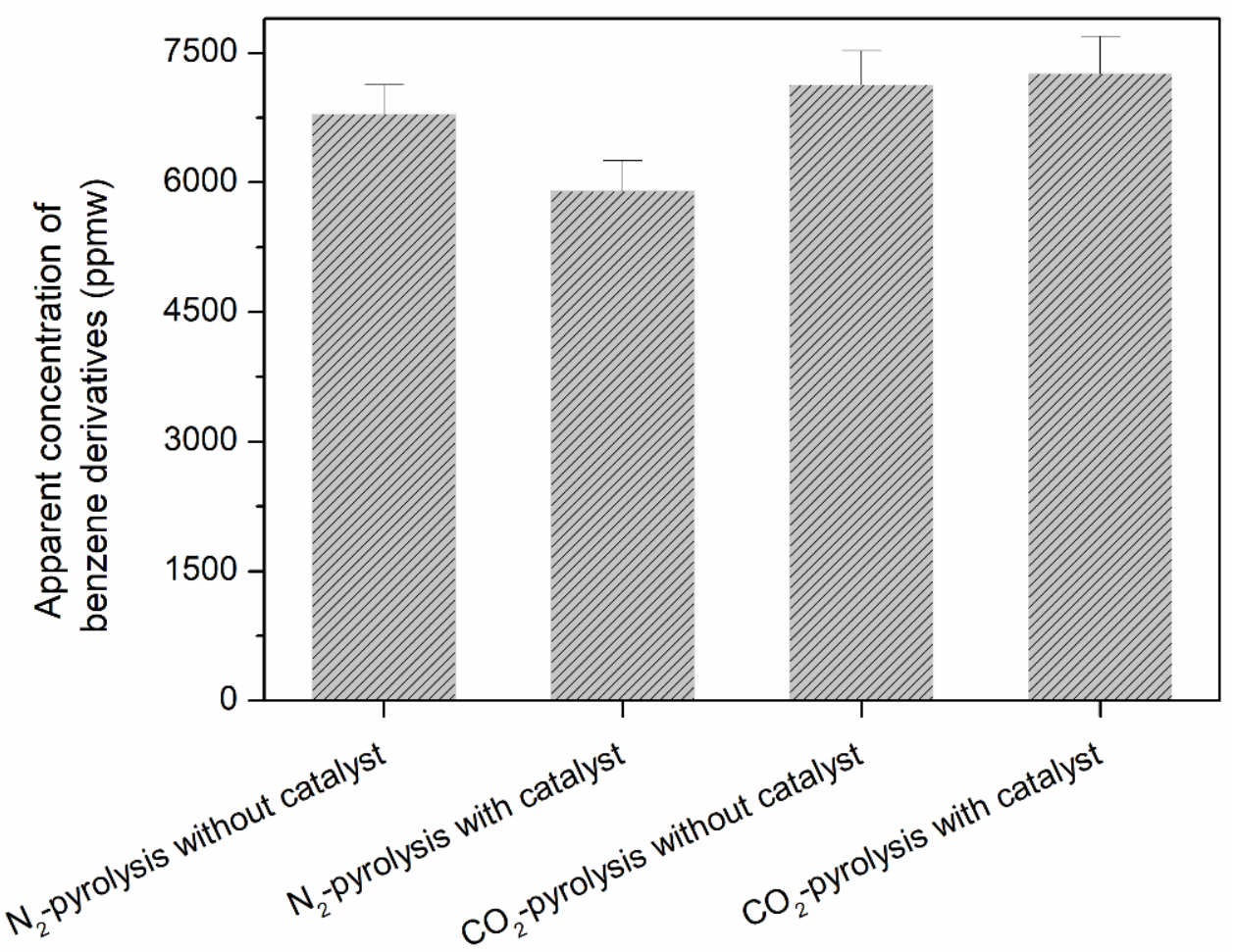

Figure 3. Comparison of total concentrations of benzene derivatives produced via the pyrolysis of the herbal medicine waste in four different conditions. Apparent concentration was determined by GC-MS using phenol as an internal standard. Mean values of replicates $(n=3)$ are reported with standard deviations given as error bars.

Figure 4 presents a composition of the pyrolytic gas evolved from the pyrolysis of the herbal medicine waste under four pyrolysis conditions. Hydrogen $\left(\mathrm{H}_{2}\right)$, carbon monoxide $(\mathrm{CO})$, and methane $\left(\mathrm{CH}_{4}\right)$ were the major components identified in the pyrolytic gas of the herbal medicine waste. No matter which pyrolysis medium was used, the use of the Pt/AC catalyst increased the $\mathrm{H}_{2}$ composition and decreased the $\mathrm{CO}$ and $\mathrm{CH}_{4}$ compositions. This may be because the $\mathrm{Pt}$ catalyst enhanced the thermal dehydrogenation of the pyrolysate of the herbal medicine waste [39]. 


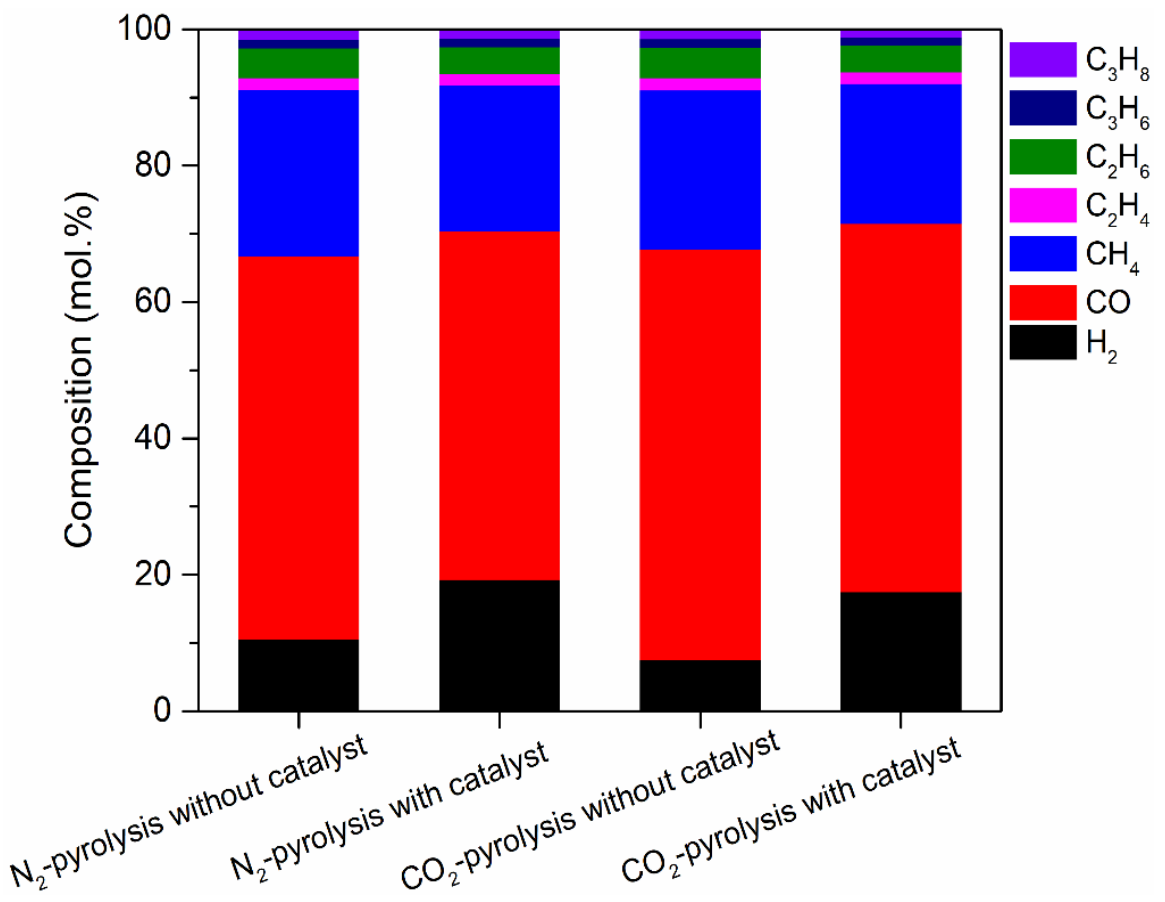

Figure 4. Composition of pyrolytic gas evolved from the pyrolysis of the herbal medicine waste in four different conditions. Note that $\mathrm{CO}_{2}$ is intentionally excluded in this figure, because the condensed $\mathrm{CO}_{2}$ concentration was measured for the catalytic and non-catalytic $\mathrm{CO}_{2}$ pyrolysis experiments in our micro GC. The composition data including $\mathrm{CO}_{2}$ for the catalytic and non-catalytic $\mathrm{N}_{2}$ pyrolysis experiments are given in Figure S3 in the Supporting information. Mean values of replicates $(n=3)$ are reported and standard deviations of the mean values are around $5 \%$.

\section{Materials and Methods}

\subsection{Materials and Reagents}

Herbal medicine waste was collected from a local oriental medical clinic (Buan County, North Jeolla, Korea), as shown in Figure 1a. The collected herbal medicine waste was dried at $60^{\circ} \mathrm{C}$ for $1 \mathrm{~d}$, pulverized, and sieved. The sieved particle size was between 200 and $600 \mu \mathrm{m}$. The pulverized sieved powder of the herbal medicine waste (Figure 1b) was used for further experiments. A Pt/AC catalyst (product number: 205931) was supplied from Sigma-Aldrich (St. Louis, MO, USA). $\mathrm{N}_{2}(\geq 99.999 \%)$ and $\mathrm{CO}_{2}(\geq 99.999 \%)$ gases were purchased from DK gas (Hwaseong, Gyeonggi, Korea).

\subsection{Characteristic Analysis}

Proximate analysis of the herbal medicine waste was conducted using a muffle furnace (model: FHX-05; DAIHAN Scientific Co., Ltd., Wonju, Gangwon, Korea) according to follow conditions [40]: moisture content: $105^{\circ} \mathrm{C}$ for $1 \mathrm{~d}$ in an open-top porcelain crucible; volatile matter (mobile matter): $450{ }^{\circ} \mathrm{C}$ for $1 \mathrm{~h}$ in a covered porcelain crucible; ash: $750{ }^{\circ} \mathrm{C}$ for $1 \mathrm{~h}$ in the open-top porcelain crucible. The content of fixed matter was determined by subtracting the sum of moisture, volatile matter, and ash contents from the sample weight. Ultimate analysis of the herbal medicine waste was conducted to determine its elemental composition $(\mathrm{C}, \mathrm{H}, \mathrm{O}, \mathrm{N}$, and $\mathrm{S}$ ) using an elemental analyzer (model: FlashSmart 2000; Thermo Scientific, Waltham, MA, USA). For characterizing the contents of C, H, $\mathrm{N}$, and $\mathrm{S}$, the sample was combusted at $1000^{\circ} \mathrm{C}$ with tungstic anhydride and copper wire catalysts. For characterizing the content of $\mathrm{O}$, the sample was combusted at $1060^{\circ} \mathrm{C}$ with nickel-plated carbon and quartz-turning catalysts. Component analysis of the herbal medicine waste was performed according to a method previously reported by Mansor et al. [41]. 


\subsection{Pyrolysis Experiments and Product Analysis}

Figure S2 schematically describes the pyrolysis reactor setup used in this study. A quartz tube (inside diameter: $21 \mathrm{~mm}$, outside diameter: $25 \mathrm{~mm}$, and length: $600 \mathrm{~mm}$ ) was used as a continuous-flow reactor for the pyrolysis of herbal medicine waste. A hinged tube furnace equipped with a temperature controller (model: HTF-Q60; Hantech Co., Ltd., Gunpo, Gyeonggi, Korea) was used to heat the reactor to $500{ }^{\circ} \mathrm{C}$ (heating rate: $10^{\circ} \mathrm{C} \mathrm{min}-1$ ) and maintain the pyrolysis temperature. According to previous studies on the pyrolysis of lignocellulosic biomass feedstocks under $\mathrm{CO}_{2}$ atmosphere [42-44], at $500{ }^{\circ} \mathrm{C}$, the effect of $\mathrm{CO}_{2}$ on the biomass pyrolysis begins to be exhibited, while the Boudouard reaction does not favor. The temperature $\left(500^{\circ} \mathrm{C}\right)$ and the heating rate $\left(10^{\circ} \mathrm{C} \mathrm{min}^{-1}\right)$ were selected based on the previous reports. The flow rate of gaseous pyrolysis medium $\left(\mathrm{N}_{2}\right.$ or $\left.\mathrm{CO}_{2}\right)$ was constant during the pyrolysis ( $300 \mathrm{~mL} \mathrm{~min}^{-1}$ ), which was controlled by an individual mass flow controller (model: 3660 Series; KOFLOC, Kyoto, Japan). The feedstock $(1 \mathrm{~g})$ and catalyst (the weight ratio of the Pt/AC catalyst to the feedstock of 0.01 ) were loaded on an alumina boat, and the feedstock and catalyst-loaded alumina boat was located at the center of the quartz tube reactor. The following four pyrolysis cases were considered in this study: (1) pyrolysis without catalyst under flowing $\mathrm{N}_{2}$ gas; (2) pyrolysis with the $\mathrm{Pt} / \mathrm{AC}$ catalyst under flowing $\mathrm{N}_{2}$ gas; (3) pyrolysis without catalyst under flowing $\mathrm{CO}_{2}$ gas; and (4) pyrolysis with the Pt/AC catalyst under flowing $\mathrm{CO}_{2}$ gas. In cases (2) and (4), in situ catalytic pyrolysis (i.e., the feedstock and catalyst are mixed before pyrolysis) was applied in this study with the ratio of the Pt/AC catalyst to the feedstock of 0.01 (weight basis). Each pyrolysis experiment was repeated three times.

Pyrolytic products passed through three consecutive cold traps $\left(-5^{\circ} \mathrm{C}\right)$ were to be condensed. The condensed pyrolytic products were analyzed using an Agilent (Santa Clara, CA, USA) gas chromatograph-mass spectrometry (GC-MS) instrument (GC model: 7890A; MS model: 5975C) equipped with an Agilent HP-5MS UI column (part number: 19091S-433UI; diameter: $0.25 \mathrm{~mm}$, length: $30 \mathrm{~m}$, and film thickness: $0.25 \mu \mathrm{m}$ ). Helium was used as a carrier gas with a flow rate of $1 \mathrm{~mL}$ $\mathrm{min}^{-1}$. The oven setting for the column temperature was: $50{ }^{\circ} \mathrm{C}$ (holding for $4 \mathrm{~min}$ ) $\rightarrow$ heating to $300{ }^{\circ} \mathrm{C}$ with a ramping rate of $5{ }^{\circ} \mathrm{C} \mathrm{min}^{-1} \rightarrow 300{ }^{\circ} \mathrm{C}$ (holding for $16 \mathrm{~min}$ ). The injector temperature, aux temperature, MS source temperature, and MS quadruple temperature were set to 280, 300, 230, and $150{ }^{\circ} \mathrm{C}$, respectively. The gain factor was 5, and the scan range was between 45 and $550 \mathrm{amu}$. Each GC-MS peak was identified using the National Institute of Standards and Technology (NIST) mass spectral library. Each identified peak was integrated, and the apparent concentration of each species was calculated based on an internal standard, phenol $\left(10 \mathrm{ng} \mathrm{mL}^{-1}\right)$. It was used as the internal standard because it was not detected in any samples obtained from the pyrolysis. Non-condensable pyrolytic gas composition was analyzed using an INFICON (Bad Ragaz, Switzerland) micro GC (model: Fusion Gas Analyzer), which was connected to the reactor outlet.

\section{Conclusions}

In this study, real herbal medicine waste was collected from a local oriental medical clinic, which was pyrolyzed. In order to suppress the generation of benzene derivatives that can be harmful to the environment and the human health for the pyrolysis of the herbal medicine waste, effects of pyrolysis medium $\left(\mathrm{N}_{2}\right.$ or $\left.\mathrm{CO}_{2}\right)$ and $\mathrm{Pt} / \mathrm{AC}$ catalyst (the ratio of catalyst/herbal medicine waste $=1 \mathrm{wt} \%$ ) on the pyrolysis at $500{ }^{\circ} \mathrm{C}$ were investigated. The results proved that the employment of the $\mathrm{Pt} / \mathrm{AC}$ catalyst decreased the contents of benzyl compounds in the pyrolytic products produced from the pyrolysis of the herbal medicine waste. The Pt/AC catalyst had an effect on the decrease in the concentrations of benzene derivatives in the pyrolytic product of the herbal medicine waste by accelerating the free radical mechanism occurring in the pyrolysis of the herbal medicine waste. However, the use of $\mathrm{CO}_{2}$ as a pyrolysis medium instead of typical inert gas (i.e., $\mathrm{N}_{2}$ ) did not quite affect the concentrations of benzyl compounds contained in the pyrolytic products of the herbal medicine waste. This study experimentally showed that the $\mathrm{Pt}$ catalyst is effective in suppressing the formation of benzene 
derivatives (e.g., dihydroxybenzenes) with enhancing $\mathrm{H}_{2}$ production during the pyrolysis of the herbal medicine waste under $\mathrm{N}_{2}$ atmosphere.

Supplementary Materials: The following are available online http://www.mdpi.com/2073-4344/10/8/826/s1, Figure S1: (a) Representative TEM image of the Pt/AC catalyst; and (b) particle size distribution of the Pt/AC catalyst, Figure S2: Schematic of the pyrolysis reactor setup used in this study, Figure S3: Composition of pyrolytic gas (including $\mathrm{CO}_{2}$ ) evolved from the non-catalytic and catalytic $\mathrm{N}_{2}$ pyrolysis of the herbal medicine waste.

Author Contributions: Conceptualization, S.J. and J.L.; investigation, Y.L., S.K. and J.K.; writing-original draft preparation, Y.L. and J.L.; writing—review and editing, Y.L., S.J. and J.L.; visualization, G.-A.S. and C.-G.L.; supervision, S.J. and J.L. All authors have read and agree to the published version of the manuscript.

Funding: This research was supported by the Ajou University research fund.

Conflicts of Interest: The authors declare no conflict of interest.

\section{References}

1. World Health Organization. Traditional Medicine Strategy 2002-2005; (WHO/EDM/TRM/2002.1); WHO: Geneva, Switzerland, 2002.

2. Hexa Research. Herbal Medicine Market Size and Forecast, By Product (Tablets \& Capsules, Powders, Extracts), By Indication (Digestive Disorders, Respiratory Disorders, Blood Disorders), And Trend Analysis, 2014-2024. 2017. Available online: https://www.hexaresearch.com/research-report/global-herbal-medicinemarket (accessed on 14 April 2020).

3. MarketWatch. Herbal Medicine Market Research Reports 2019. Global Industry Size, Share, Emerging Trends, Growth Boosted By Demand and Advanced Technology till 2023. 2019. Available online: https://www. marketwatch.com/press-release/herbal-medicine-market-research-reports-2019-global-industry-size-

share-emerging-trends-growth-boosted-by-demand-and-advanced-technology-till-2023-2019-2010-2002 (accessed on 14 April 2020).

4. Mi, T.; Yu, X.-M. Study on fluidization characteristics of chinese herbal medicine waste in a fluidized bed reactor. Appl. Mech. Mater. 2012, 138, 952-957. [CrossRef]

5. Soetrisnanto, D.; Christwardana, M.; Hadiyanto, H. Application of phytoremediation for herbal medicine waste and its utilization for protein production. Reaktor 2012, 14, 129-134. [CrossRef]

6. Chen, M.; Tang, R.; Fu, G.; Xu, B.; Zhu, P.; Qiao, S.; Chen, X.; Xu, B.; Qin, Y.; Lu, C.; et al. Association of exposure to phenols and idiopathic male infertility. J. Hazard. Mater. 2013, 250, 115-121. [CrossRef] [PubMed]

7. Zhou, M.; Zhang, J.; Sun, C. Occurrence, ecological and human health risks, and seasonal variations of phenolic compounds in surface water and sediment of a potential polluted river basin in China. Int. J. Environ. Res. Public Health 2017, 14, 1140. [CrossRef]

8. Ali, M.; Duba, K.S.; Kalamdhad, A.S.; Bhatia, A.; Khursheed, A.; Kazmi, A.A.; Ahmed, N. High rate composting of herbal pharmaceutical industry solid waste. Water Sci. Technol. 2012, 65, 1817-1825. [CrossRef]

9. Kwon, E.E.; Lee, T.; Ok, Y.S.; Tsang, D.C.W.; Park, C.; Lee, J. Effects of calcium carbonate on pyrolysis of sewage sludge. Energy 2018, 153, 726-731. [CrossRef]

10. Kim, S.; Lee, Y.; Andrew Lin, K.-Y.; Hong, E.; Kwon, E.E.; Lee, J. The valorization of food waste via pyrolysis. J. Clean. Prod. 2020, 259, 120816. [CrossRef]

11. Ryu, S.; Lee, H.W.; Kim, Y.-M.; Jae, J.; Jung, S.-C.; Ha, J-M.; Park, Y.-K. Catalytic fast co-pyrolysis of organosolv lignin and polypropylene over in-situ red mud and ex-situ HZSM-5 in two-step catalytic micro reactor. Appl. Surf. Sci. 2020, 511, 145521. [CrossRef]

12. Lam, S.S.; Wan Mahari, W.A.; Ok, Y.S.; Peng, W.; Chong, C.T.; Ma, N.L.; Chase, H.A.; Liew, Z.; Yusup, S.; Kwon, E.E.; et al. Microwave vacuum pyrolysis of waste plastic and used cooking oil for simultaneous waste reduction and sustainable energy conversion: Recovery of cleaner liquid fuel and techno-economic analysis. Renew. Sust. Energ. Rev. 2019, 115, 109359. [CrossRef]

13. Lee, J.; Kwon, E.E.; Park, Y.-K. Recent advances in the catalytic pyrolysis of microalgae. Catal. Today 2019. [CrossRef]

14. Oyedun, A.O.; Lam, K.L.; Hui, C.W. Charcoal production via multistage pyrolysis. Chin. J. Chem. Eng. 2012, 20, 455-460. [CrossRef] 
15. Alonso, M.Z.; Tran, K.-Q.; Wang, L.; Skreiberg, Ø. A kinetic study on simultaneously boosting the mass and fixed-carbon yield of charcoal production via atmospheric carbonization. Energy Proc. 2017, 120, 333-340. [CrossRef]

16. Demirbas, A.; Ahmad, W.; Alamoudi, R.; Sheikh, M. Sustainable charcoal production from biomass. Energy Sources Part A 2016, 38, 1882-1889. [CrossRef]

17. Yek, P.N.Y.; Liew, R.K.; Osman, M.S.; Lee, C.L.; Chuah, J.H.; Park, Y.-K.; Lam, S.S. Microwave steam activation, an innovative pyrolysis approach to convert waste palm shell into highly microporous activated carbon. J. Environ. Manag. 2019, 236, 245-253. [CrossRef] [PubMed]

18. Lam, S.S.; Su, M.H.; Nam, W.L.; Thoo, D.S.; Ng, C.M.; Liew, R.K.; Yuh Yek, P.N.; Ma, N.L.; Nguyen Vo, D.V. Microwave pyrolysis with steam activation in producing activated carbon for removal of herbicides in agricultural surface water. Ind. Eng. Chem. Res. 2019, 58, 695-703. [CrossRef]

19. Azwar, E.; Wan Mahari, W.A.; Chuah, J.H.; Vo, D.-V.N.; Ma, N.L.; Lam, W.H.; Lam, S.S. Transformation of biomass into carbon nanofiber for supercapacitor application-A review. Int. J. Hydrog. Energy 2018, 43, 20811-20821. [CrossRef]

20. Jung, J.-M.; Oh, J.-I.; Baek, K.; Lee, J.; Kwon, E.E. Biodiesel production from waste cooking oil using biochar derived from chicken manure as a porous media and catalyst. Energy Convers. Manag. 2018, 165, 628-633. [CrossRef]

21. Kim, S.; Park, C.; Lee, J. Reduction of polycyclic compounds and biphenyls generated by pyrolysis of industrial plastic waste by using supported metal catalysts: A case study of polyethylene terephthalate treatment. J. Hazard. Mater. 2020, 392, 122464. [CrossRef]

22. Lee, Y.; Kim, S.; Kwon, E.E.; Lee, J. Effect of carbon dioxide on thermal treatment of food waste as a sustainable disposal method. J. $\mathrm{CO}_{2}$ Util. 2020, 36, 76-81. [CrossRef]

23. Kim, S.; Lee, J. Pyrolysis of food waste over a Pt catalyst in $\mathrm{CO}_{2}$ atmosphere. J. Hazard. Mater. 2020, 393, 122449. [CrossRef]

24. Kobayashi, H.; Fukuoka, A. Current catalytic processes for biomass conversion. In New and Future Developments in Catalysis; Suib, S.L., Ed.; Elsevier: Amsterdam, The Netherlands, 2013; pp. $29-52$.

25. Kim, S.; Tsang, Y.F.; Kwon, E.E.; Lin, K.-Y.A.; Lee, J. Recently developed methods to enhance stability of heterogeneous catalysts for conversion of biomass-derived feedstocks. Korean J. Chem. Eng. 2019, 36, 1-11. [CrossRef]

26. Kim, S.; Kwon, E.E.; Kim, Y.T.; Jung, S.; Kim, H.J.; Huber, G.W.; Lee, J. Recent advances in hydrodeoxygenation of biomass-derived oxygenates over heterogeneous catalysts. Green Chem. 2019, 21, 3715-3743. [CrossRef]

27. Jenkins, N.; Ekanayake, J. Bioenergy. In Renewable Energy Engineering; Cambridge University Press: Cambridge, UK, 2017.

28. NCBI. National Center for Biotechnology Information. PubChem Database. Catechol, CID=289. Available online: https://pubchem.ncbi.nlm.nih.gov/compound/Catechol\#datasheet=LCSS (accessed on 18 April 2020).

29. NCBI. National Center for Biotechnology Information. PubChem Database. Hydroquinone, $\mathrm{CID}=785$. Available online: https://pubchem.ncbi.nlm.nih.gov/compound/Hydroquinone\#datasheet=LCSS (accessed on 18 April 2020).

30. NCBI. National Center for Biotechnology Information. PubChem Database. Indole, CID=798. Available online: https://pubchem.ncbi.nlm.nih.gov/compound/Indole\#datasheet=LCSS (accessed on 18 April 2020).

31. Huang, W.-Y.; Cai, Y.-Z.; Zhang, Y. Natural phenolic compounds from medicinal herbs and dietary plants: Potential use for cancer prevention. Nutr. Cancer 2009, 62, 1-20. [CrossRef] [PubMed]

32. Liu, C.; Wang, H.; Karim, A.M.; Sun, J.; Wang, Y. Catalytic fast pyrolysis of lignocellulosic biomass. Chem. Soc. Rev. 2014, 43, 7594-7623. [CrossRef] [PubMed]

33. Wang, S.; Hu, Y.; Uzoejinwa, B.B.; Cao, B.; He, Z.; Wang, Q.; Xu, S. Pyrolysis mechanisms of typical seaweed polysaccharides. J. Anal. Appl. Pyrol. 2017, 124, 373-383. [CrossRef]

34. Yanishlieva, N.; Schiller, H.; Marinova, E. Autoxidation of sitosterol. II: Main products formed at ambient and high temperature treatment with oxygen. Riv. Ital. Sostanze Grasse 1980, 57, 572-576.

35. Cert, A.; Lanzón, A.; Carelli, A.A.; Albi, T.; Amelotti, G. Formation of stigmasta-3,5-diene in vegetable oils. Food Chem. 1994, 49, 287-293. [CrossRef]

36. Ye, J.-C.; Chang, W.-C.; Hsieh, D.J.-Y.; Hsiao, M.-W. Extraction and analysis of $\beta$-sitosterol in herbal medicines. J. Med. Plant Res. 2010, 4, 522-527. 
37. Greensfelder, B.S.; Voge, H.H.; Good, G.M. Catalytic and thermal cracking of pure hydrocarbons: Mechanisms of reaction. Ind. Eng. Chem. 1949, 41, 2573-2584. [CrossRef]

38. Marcinkowski, M.D.; Darby, M.T.; Liu, J.; Wimble, J.M.; Lucci, F.R.; Lee, S.; Michaelides, A.; Flytzani-Stephanopoulos, M.; Stamatakis, M.; Sykes, E.C.H. Pt/Cu single-atom alloys as coke-resistant catalysts for efficient C-H activation. Nat. Chem. 2018, 10, 325. [CrossRef]

39. Cho, S.-H.; Lee, S.S.; Jung, S.; Park, Y.-K.; Lin, K.-Y.A.; Lee, J.; Kwon, E.E. Carbon dioxide-cofeeding pyrolysis of pine sawdust over nickle-based catalyst for hydrogen production. Energy Convers. Manag. 2019, 201, 112140. [CrossRef]

40. Ahmad, M.; Lee, S.S.; Rajapaksha, A.U.; Vithanage, M.; Zhang, M.; Cho, J.S.; Lee, S.-E.; Ok, Y.S. Trichloroethylene adsorption by pine needle biochars produced at various pyrolysis temperatures. Bioresour. Technol. 2013, 143, 615-622. [CrossRef] [PubMed]

41. Mansor, A.M.; Lim, J.S.; Ani, F.N.; Hashim, H.; Ho, W.S. Characteristics of cellulose, hemicellulose and lignin of MD2 pineapple biomass. Chem. Eng. Trans. 2019, 72, 79-84.

42. Choi, D.; Oh, J.-I.; Baek, K.; Lee, J.; Kwon, E.E. Compositional modification of products from co-pyrolysis of chicken manure and biomass by shifting carbon distribution from pyrolytic oil to syngas using $\mathrm{CO}_{2}$. Energy 2018, 153, 530-538. [CrossRef]

43. Cho, S.-H.; Lee, J.; Kim, K.-H.; Jeon, Y.J.; Kwon, E.E. Carbon dioxide assisted co-pyrolysis of coal and ligno-cellulosic biomass. Energy Convers. Manag. 2016, 118, 243-252. [CrossRef]

44. Lee, J.; Yang, X.; Cho, S.-H.; Kim, J.-K.; Lee, S.S.; Tsang, D.C.W.; Ok, Y.S.; Kwon, E.E. Pyrolysis process of agricultural waste using $\mathrm{CO}_{2}$ for waste management, energy recovery, and biochar fabrication. Appl. Energy 2017, 185, 214-222. [CrossRef]

(C) 2020 by the authors. Licensee MDPI, Basel, Switzerland. This article is an open access article distributed under the terms and conditions of the Creative Commons Attribution (CC BY) license (http://creativecommons.org/licenses/by/4.0/). 